\title{
Worse Outcome in Stroke Patients Treated with rt-PA Without Early Reperfusion: Associated Factors
}

\author{
Ramón Iglesias-Rey $^{1}$ (D) Manuel Rodríguez-Yáñez ${ }^{1} \cdot$ Emilio Rodríguez-Castro $^{1} \cdot$ \\ José Manuel Pumar ${ }^{2}$ - Susana Arias ${ }^{1}$ - María Santamaría ${ }^{1}$. Iria López-Dequidt ${ }^{1}$. \\ Pablo Hervella ${ }^{1}$ - Clara Correa-Paz ${ }^{1}$ - Tomás Sobrino ${ }^{1}$ - Denis Vivien ${ }^{3,4}$. \\ Francisco Campos ${ }^{1} \cdot$ Mar Castellanos $^{5}$. José Castillo ${ }^{1}$
}

Received: 27 September 2017 / Revised: 23 October 2017 / Accepted: 30 October 2017 / Published online: 7 November 2017

(C) The Author(s) 2017. This article is an open access publication

\begin{abstract}
Based on preclinical studies suggesting that recombinant tissue plasminogen activator (rt-PA) may promote ischemic brain injuries, we investigated in patients the possible risk of worse clinical outcome after rt-PA treatment as a result of its inability to resolve cerebral ischemia. Here, we designed a cohort study using a retrospective analysis of patients who received treatment with intravenous $(4.5-\mathrm{h}$ window) or intraarterial rt-PA, without or with thrombectomy. Controls were consecutive patients who did not receive recanalization treatment, who met all inclusion criteria. As a marker of reperfusion, we defined the variable of early neurological improvement as the difference between the score of the National Institute of Health Stroke Scale (NIHSS) (at admission and $24 \mathrm{~h}$ ). The main variable was worsening of the patient's
\end{abstract}

Ramón Iglesias-Rey

ramon.iglesias.rey@sergas.es

1 Clinical Neurosciences Research Laboratory, Department of Neurology, Clinical University Hospital, Universidade de Santiago de Compostela, Health Research Institute of Santiago de Compostela (IDIS), 15706 Santiago de Compostela, Spain

2 Department of Neuroradiology, Clinical University Hospital, Universidade de Santiago de Compostela, Health Research Institute of Santiago de Compostela (IDIS), 15706 Santiago de Compostela, Spain

3 Inserm, Inserm, UMR-S U1237, Physiopathology and Imaging of Neurological diseases, GIP Cyceron, Caen Normandie University, 14073 Caen, France

4 CHU de Caen, Department of Clinical Research, Caen University Hospital, 14000 Caen, France

5 Department of Neurology, Biomedical Research Institute, University Hospital A Coruña, 15006 Corunna, Spain functional situation in the first 3 months. To compare quantitative variables, we used Student's $t$ test or the Mann-Whitney test. To estimate the odds ratios of each independent variable in the patient's worsening in the first 3 months, we used a logistic regression model. We included 1154 patients; 577 received rt-PA, and 577 served as controls. In the group of patients treated with rt-PA, $39.4 \%$ who did not present clinical reperfusion data developed worsening within 3 months after stroke compared with $3.5 \%$ of patients with reperfusion $(P<0.0001)$. These differences were not significant in the control group. In summary, administration of rt-PA intravenously or intraarterially without reperfusion within the first $24 \mathrm{~h}$ may be associated with a higher risk of functional deterioration in the first 3 months.

Keywords Blood-brain barrier · Critical care $\cdot$ Hemorrhage transformation $\cdot$ Ischemic stroke $\cdot$ Prognosis

\section{Introduction}

Stroke is the second leading cause of death in developed countries, the second leading cause of dementia, and the leading cause of major disability in adults, with an increasing incidence because of the progressive aging of the population in such countries. Since 1995, despite its complications, recombinant tissue plasminogen activator (rt-PA) administered intravenously alone or subsequently in combination with intraarterial administration or with mechanical thrombectomy is the only drug treatment for acute ischemic stroke [1-7]. Besides the unquestionable benefit from its thrombolytic activity, consistent evidence has accumulated on the neurotoxic effect of rt-PA both in vitro and in vivo, including in experimental models of cerebral ischemia [8-14]. Mechanisms by which rt-PA causes these neurotoxic effects 
have not been fully elucidated, mainly due to their multifactorial and time-dependent activity.

The clinical evidence on the neurotoxicity associated with rt-PA treatment following ischemic stroke is still debated, and it is of crucial importance to reduce risks after administration of the thrombolytic agent for a better patient management $[15,16]$. In the present work, we thus decided to set-up a clinical study based on the hypothesis that rt-PA could be a "Janus" drug. Our hypothesis was based on two possible scenarios: (1) If the thrombolytic activity of rt-PA is effective and cerebral ischemia rapidly resolved, the blood-brain barrier remains intact with the rt-PA maintained within the vascular compartment, thus leading to a better clinical outcome; (2) if the rt-PA cannot play its thrombolytic action thus leading to a prolonged cerebral ischemia, rt-PA could then enhance damages of the blood-brain barrier and of the cerebral parenchyma, thus leading to a worse clinical outcome [17].

\section{Materials and Methods}

\section{Study Design}

A retrospective cohort study $(n=1154)$ was designed using a prospective registry of acute ischemic stroke patients (BICHUS) approved by the Ethics Committee of Galicia.

Between January 2008 and October 2016, 577 patients who were treated with intravenous (with ECASS II criteria [18] modified with a therapeutic window $\leq 4.5 \mathrm{~h}$ and with no age limit) or intraarterial rt-PA, without or with thrombectomy (who previously received rt-PA), were analyzed to be included in the study. On the other hand, 577 controls were defined as ischemic stroke patients not treated with rt-PA, who were selected after each case included. Both groups met all the inclusion criteria and none of the exclusion criteria.

\section{Inclusion and Exclusion Criteria}

The inclusion criteria were as follows: (1) Ischemic stroke patients attended by a neurologist according to common protocol [19] and admitted to the stroke unit, (2) fewer than $6 \mathrm{~h}$ of evolution (no wake-up strokes were included), (3) neuroimaging on admission, (4) previous modified Rankin Scale $(\mathrm{mRS})<2$, and (5) without previous stroke and without lacunar syndrome (LACI).

The exclusion criteria were as follows: (1) institutionalized patients, (2) comorbidity and life expectancy $<1$ year, (3) without subsequent diagnostic confirmation, (4) lacunar infarctions, and (5) loss of follow-up at 3 months were excluded.

\section{Clinical Variables}

The clinical variables analyzed were age, sex, axillary temperature at admission, history of arterial hypertension (at least two blood pressure measurements greater than 140/ $85 \mathrm{mmHg}$ or with antihypertensive treatment), diabetes (previous diagnosis or with antidiabetic treatment), alcoholism (> $300 \mathrm{~g}$ of alcohol per week), smoking (habitual smoker or until the last year), dyslipidemia (at least a previous determination of total cholesterol $>230 \mathrm{mg} / \mathrm{dL}$ or antihyperlipidemic treatment), peripheral arterial disease, coronary disease, atrial fibrillation, known carotid disease, and prior transient ischemic attack. Classification according to Oxfordshire Community Stroke Project (OSCP) criteria [20], National Institute of Health Stroke Scale (NIHSS) at entry and at $24 \mathrm{~h}$, start-inclusion time and start-needle time, TOAST classification [21], hemorrhage transformation (according to ECASS II criteria [18]), and mRS at discharge and at 3 months. An accredited neurologist rated the scales. For this study, blood glucose, leukocytes, fibrinogen, C-reactive protein, erythrocyte sedimentation rate, and albumin per gram of creatinine were collected at the time of admission. A second neuroimaging study was performed on all patients between the fourth and seventh day after admission or immediately if neurological impairment was detected (defined as the $\geq 4$ point increase in NIHSS). During their hospitalization and after hospital discharge, the patients were attended by physicians and physiotherapists of the Rehabilitation Service of the Clinical University Hospital of Santiago de Compostela.

\section{Main Outcomes}

According to previous studies [22-24], as a marker of reperfusion, we defined the variable of early neurological improvement as the difference between the score of the NIHSS determined at admission and at $24 \mathrm{~h}$ (an improvement of 8 points in NIHSS). The study's main variable was the worsening of the patient's functional situation in the first 3 months. This variable was determined as the difference of the mRS between hospital discharge and 3 months \pm 15 days (mRS from discharge to 3 months). We defined the worsening as a value $\mathrm{mRS}$ from discharge to 3 months $<0$. Death at any time since inclusion of the patient was classified as worsening. An mRS at 3 months $\leq 2$ was defined as a good outcome.

\section{Statistical Analyses}

Results were expressed as percentages for categorical variables and as mean (standard deviation [S.D.]) or median and range (25th and 75th percentiles) for the continuous variables, depending on whether their distribution was normal. The Kolmogorov-Smirnov test was used for testing the normality of the distribution. Proportions were compared using the chi- 
square or Fisher test, while continuous variables between groups were compared with Student's $t$ or the MannWhitney tests, depending on whether their distribution was normal. Bivariate correlations were performed using Pearson's (normally distributed variables) or Spearman (variables without normal distribution) coefficients.
The association of fibrinolytic treatment, with and without reperfusion, on worsening functional outcome (mRS from discharge to 3 months $<0$ ) was assessed by logistic regression analysis models. Each logistic regression analysis model was adjusted for the independent variables in the bivariate analysis. Results were expressed as adjusted odds ratios (ORs) with
Table 1 Bivariate analysis between patients treated (fibrinolytic therapy group) and not treated (control group) with rtPA

\begin{tabular}{|c|c|c|c|}
\hline & $\begin{array}{l}\text { Fibrinolytic therapy } \\
n=577\end{array}$ & $\begin{array}{l}\text { Control } \\
n=577\end{array}$ & $P$ \\
\hline Age, years & $71.7 \pm 12.2$ & $70.7 \pm 13.4$ & 0.062 \\
\hline Men, $\%$ & 50.4 & 55.3 & 0.111 \\
\hline Previous mRS & $0[0,1]$ & $0[0,1]$ & 0.054 \\
\hline History of high blood pressure, $\%$ & 62.4 & 60.7 & 0.586 \\
\hline History of diabetes, $\%$ & 19.4 & 23.7 & 0.086 \\
\hline History of alcoholism, $\%$ & 8.7 & 11.3 & 0.169 \\
\hline History of smoking, $\%$ & 13.9 & 15.6 & 0.455 \\
\hline History of dyslipidemia, $\%$ & 40.2 & 40.4 & 1.000 \\
\hline Peripheral arterial disease, $\%$ & 7.1 & 5.7 & 0.400 \\
\hline Ischemic heart disease, $\%$ & 11.8 & 11.4 & 0.927 \\
\hline Atrial fibrillation, $\%$ & 21.3 & 22.7 & 0.619 \\
\hline Known carotid disease, $\%$ & 1.2 & 0.9 & 0.773 \\
\hline Previous TIAs, $\%$ & 1.9 & 0.9 & 0.207 \\
\hline OSCP & & & $<0.0001$ \\
\hline TACI, $\%$ & 45.1 & 28.8 & \\
\hline PACI, $\%$ & 48.5 & 49.4 & \\
\hline POCI, \% & 6.4 & 21.8 & \\
\hline NIHSS at admission & $14[10,18]$ & $9[6,16]$ & $<0.0001$ \\
\hline NIHSS at $24 \mathrm{~h}$ & $8[5,16]$ & $8[6,15]$ & 0.237 \\
\hline$\geq 8$ points of the NIHSS in the first $24 \mathrm{~h}, \%$ & 24.8 & 2.6 & $<0.0001$ \\
\hline Start-inclusion time, min & $175.6 \pm 40.6$ & $239.9 \pm 69.1$ & $<0.0001$ \\
\hline Start-needle time, min & $224.1 \pm 39.6$ & - & \\
\hline TOAST & & & 0.458 \\
\hline Large vessel disease, $\%$ & 33.4 & 30.7 & \\
\hline Cardioembolic, $\%$ & 39.2 & 39.0 & \\
\hline Indeterminate, $\%$ & 27.4 & 30.3 & \\
\hline Hemorrhagic transformation & & & $<0.0001$ \\
\hline Asymptomatic, $\%$ & 5.7 & 1.4 & \\
\hline Symptomatic, \% & 1.9 & 0.9 & \\
\hline $\mathrm{mRS}$ at discharge & $4[2,5]$ & $4[2,5]$ & 0.964 \\
\hline $\mathrm{mRS}$ at 3 months & $2[1,4]$ & $4[3,6]$ & $<0.0001$ \\
\hline Good outcome at 3 months, $\%$ & 53.8 & 24.1 & $<0.0001$ \\
\hline $\begin{array}{l}\text { Axillary temperature at admission, }{ }^{\circ} \mathrm{C} \\
\quad(n=1154)\end{array}$ & $36.3 \pm 0.6$ & $36.3 \pm 0.5$ & 0.926 \\
\hline Blood glucose at admission, mg/dL $(n=1154)$ & $135.7 \pm 50.4$ & $139.9 \pm 61.5$ & 0.199 \\
\hline Leukocytes at admission, $\times 10^{3} / \mathrm{mmc}(n=1154)$ & $9.1 \pm 3.4$ & $9.1 \pm 3.1$ & 0.926 \\
\hline Fibrinogen at admission, mg/dL $(n=926)$ & $416.6 \pm 116.1$ & $425.9 \pm 88.8$ & 0.176 \\
\hline $\begin{array}{l}\text { C-reactive protein at admission, } \mathrm{mg} / \mathrm{dL} \\
(n=894)\end{array}$ & $3.9 \pm 4.8$ & $3.6 \pm 3.6$ & 0.249 \\
\hline $\begin{array}{l}\text { Sedimentation rate at admission, } \mathrm{mm} / \mathrm{h} \\
\quad(n=999)\end{array}$ & $22.2 \pm 22.4$ & $24.1 \pm 21.2$ & 0.187 \\
\hline Albuminuria, $\mathrm{mg} / \mathrm{g}$ of creatinine $(n=785)$ & $7.1 \pm 33.2$ & $4.4 \pm 26.3$ & 0.199 \\
\hline
\end{tabular}


the corresponding 95\% confidence intervals ( $95 \% \mathrm{CI})$. On the other hand, receiver operating characteristic (ROC) curve analysis was used to compare the early neurological improvement and the improvement of the mRS from discharge at 3 months \pm 15 days, as a clinical marker of an effective reperfusion.

A $P$ value $<0.05$ was considered to be statistically significant in all tests. The statistical analysis was conducted in SPSS 21.0 (IBM, Chicago, IL, USA) for Mac.

\section{Results}

\section{Longitudinal Studies of Groups}

Seven-hundred three patients received fibrinolytic therapy; 499 were treated with intravenous rt-PA, 99 with intraarterial rt-PA, (with or without thrombectomy), and 105 with intravenous rt-PA plus intraarterial rt-PA (with or without thrombectomy). We excluded 126 individuals from this study: 59 were institutionalized, 44 due to lack of follow-up, 2 due to comorbidities, and 21 due to subsequent diagnostic confirmation of lacunar infarction. Therefore, 1154 patients were included in this study, 577 of whom received rt-PA (387 intravenous, 93 intraarterial, and 97 intravenous plus intraarterial with or without thrombectomy), and 577 controls.

Comparison between the rt-PA-treated group and the control group is shown in Table 1. In summary, patients receiving

a

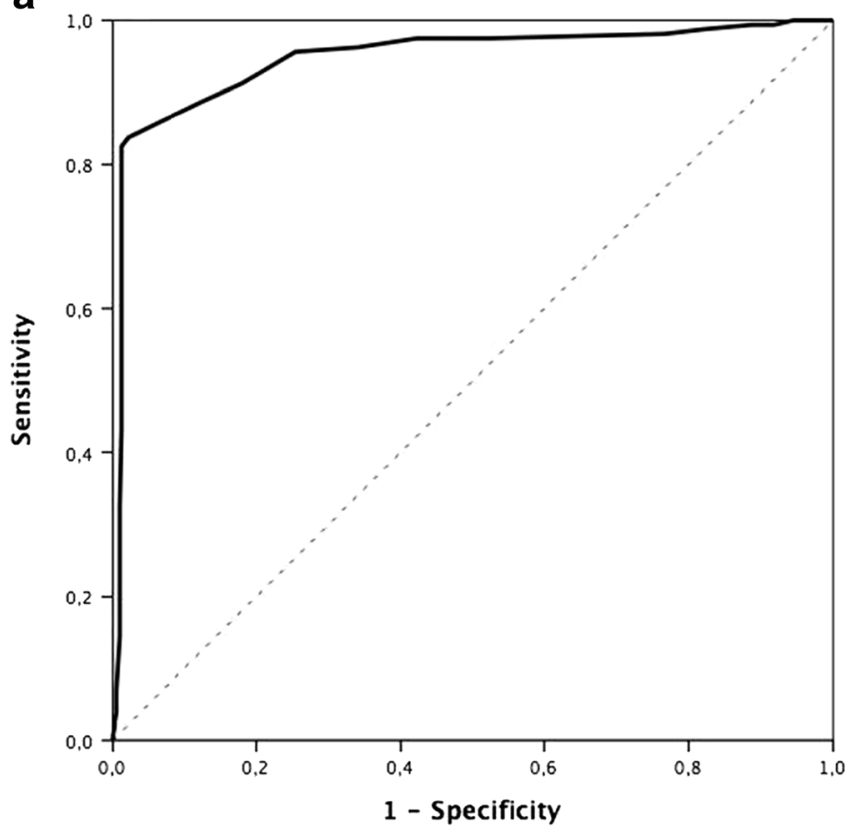

Fig. 1 ROC curve. Main variable-improvement of mRS from discharge to 3 months. Influence of the difference among the NIHSS in the first $24 \mathrm{~h}$ and the main variable. a Patients with fibrinolytic treatment. For a cutoff point of 8 , the sensitivity is $82.5 \%$ and the specificity is fibrinolytic therapy were worse neurologically on admission and were included in less time. In patients treated with rt-PA, the onset-needle time was $224.1 \pm 39.6 \mathrm{~min}$, and the percentage of hemorrhagic transformation was higher. The mRS at 3 months was better, as was the percentage of patients with a good outcome.

In our series, in patients treated with rt-PA, an improvement of 8 points in NIHSS in the first $24 \mathrm{~h}$ was identified as a clinical marker of effective reperfusion, with a sensitivity of $82.5 \%$ and a specificity of $98.8 \%$ (area under the curve 0.948 ; CI $95 \% 0.924-0.971, P<0.0001$ ). It was not possible to establish the cutoff point in the control group (Fig. 1). The percentage of patients with clinical reperfusion marker was higher in patients treated with rt-PA $(24.8$ vs. $2.6 \%, P<0.0001)$. This reperfusion was $12.1 \%$ in patients treated intravenously, $65.6 \%$ intraarterially, and $51.5 \%$ intravenously and intraarterially combined $(P<0.0001)$.

In the first 3 months of evolution, 240 patients (20.8\%) presented worsened functioning. The percentage of worsening in the reperfused patients was similar in the three therapeutic groups $(4.1,3.2$, and $3.3 \%$, respectively, $P=0.402$ ). The bivariate study (Table 2 ) among patients who worsened and those who improved $(n=461,39.2 \%)$ or remained stable $(n=453,39.9 \%)$ showed differences in the percentage of alcoholism, smoking, clinical reperfusion, and treatment with rt-PA. The time between onsetinclusion and onset-needle was greater in patients who worsened. Although mRS at discharge was better in the

b

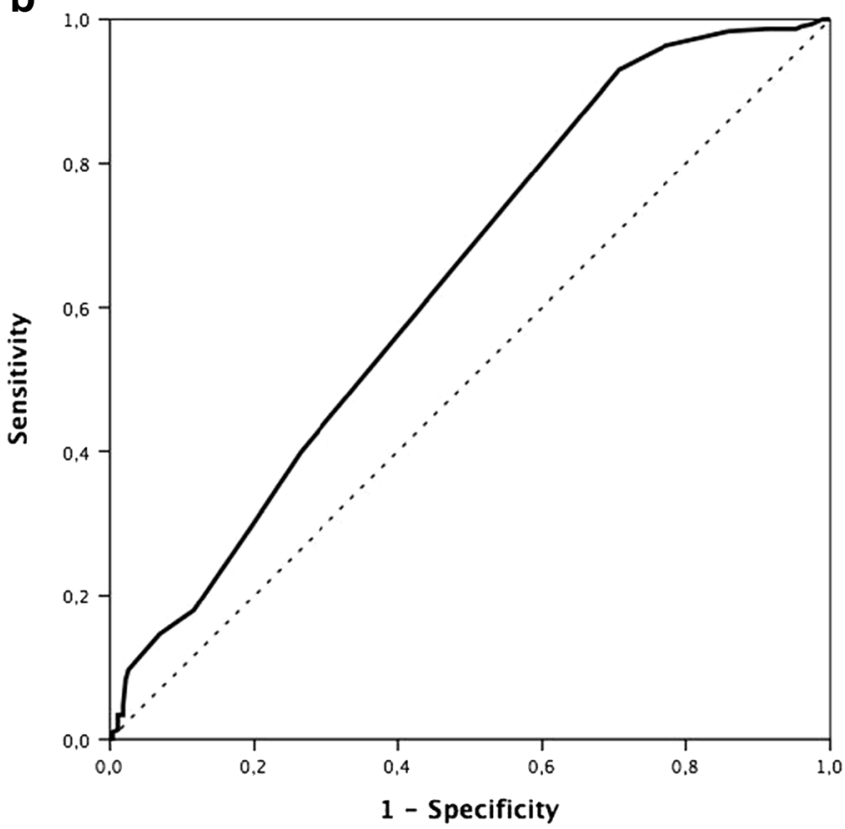

98.8\%. Area under the curve 0.948 (CI 95\% 0.924-0.971, $P<0.0001$ ). b Patients without fibrinolytic treatment. Area under the curve 0.636 (CI $95 \% 0.591-0.682, P=0.023$ ). It is not possible to establish a cutoff point 
Table 2 Bivariate analysis between the group of patients with and without functional outcome worsening ( $\mathrm{mRS}$ from discharge to 3 months $<0$ )

\begin{tabular}{|c|c|c|c|}
\hline & No $n=914$ & Yes $n=240$ & $P$ \\
\hline Age, years & $70.9 \pm 12.1$ & $72.3 \pm 11.8$ & 0.131 \\
\hline Men, $\%$ & 53.5 & 50.4 & 0.424 \\
\hline Previous $\mathrm{mRS}$ & $0[0,1]$ & $0[0,1]$ & 0.307 \\
\hline History of high blood pressure, $\%$ & 62.6 & 57.5 & 0.157 \\
\hline History of diabetes, $\%$ & 21.0 & 23.8 & 0.378 \\
\hline History of alcoholism, $\%$ & 9.0 & 13.8 & 0.039 \\
\hline History of smoking, $\%$ & 16.2 & 9.2 & 0.006 \\
\hline History of dyslipidemia, $\%$ & 39.1 & 45.0 & 0.104 \\
\hline Peripheral arterial disease, $\%$ & 6.2 & 7.1 & 0.657 \\
\hline Ischemic heart disease, $\%$ & 11.1 & 13.8 & 0.258 \\
\hline Atrial fibrillation, $\%$ & 23.2 & 17.5 & 0.066 \\
\hline Known carotid disease, $\%$ & 1.2 & 0.4 & 0.478 \\
\hline Previous TIAs, $\%$ & 1.5 & 0.8 & 0.546 \\
\hline OSCP & & & 0.094 \\
\hline TACI, $\%$ & 37.3 & 35.4 & \\
\hline PACI, $\%$ & 47.2 & 55.8 & \\
\hline POCI, \% & 15.5 & 8.8 & \\
\hline NIHSS at admission & $12[8,17]$ & $11[7,16]$ & 0.062 \\
\hline NIHSS at $24 \mathrm{~h}$ & $8[5,15]$ & $10[6,16]$ & 0.071 \\
\hline$\geq 8$ points of NIHSS in the first $24 \mathrm{~h}, \%$ & 16.5 & 2.9 & $<0.0001$ \\
\hline Start-inclusion time, $\min$ & $198.7 \pm 57.9$ & $210.1 \pm 66.7$ & 0.016 \\
\hline Start-needle time, $\min (n=577)$ & $221.5 \pm 39.6$ & $230.2 \pm 39.3$ & 0.017 \\
\hline TOAST & & & 0.535 \\
\hline Large vessel disease, $\%$ & 31.3 & 35.0 & \\
\hline Cardioembolic, $\%$ & 39.4 & 37.9 & \\
\hline Indeterminate, $\%$ & 29.3 & 27.1 & \\
\hline rt-PA treatment, $\%(n=577)$ & 43.9 & 73.3 & $<0.0001$ \\
\hline Hemorrhagic transformation & & & 0.899 \\
\hline Asymptomatic, $\%$ & 3.6 & 3.3 & \\
\hline Symptomatic, \% & 1.3 & 1.7 & \\
\hline $\mathrm{mRS}$ at discharge & $4[2,5]$ & $3[2,4]$ & $<0.0001$ \\
\hline $\mathrm{mRS}$ at 3 months & $3[1,5]$ & $4[3,5]$ & $<0.0001$ \\
\hline Good outcome at 3 months, $\%$ & 40.6 & 18.3 & $<0.0001$ \\
\hline Axillary temperature at admission, ${ }^{\circ} \mathrm{C}(n=1154)$ & $36.3 \pm 0.6$ & $36.4 \pm 0.6$ & 0.206 \\
\hline Blood glucose at admission, mg/dL $(n=1154)$ & $136.8 \pm 54.9$ & $141.8 \pm 61.0$ & 0.217 \\
\hline Leukocytes at admission, $\times 10^{3} / \mathrm{mmc}(n=1154)$ & $8.9 \pm 3.2$ & $9.2 \pm 3.2$ & 0.360 \\
\hline Fibrinogen at admission, $\mathrm{mg} / \mathrm{dL}(n=926)$ & $420.5 \pm 100.1$ & $422.2 \pm 119.7$ & 0.831 \\
\hline C-reactive protein at admission, $\mathrm{mg} / \mathrm{dL}(n=894)$ & $3.7 \pm 4.2$ & $4.1 \pm 4.9$ & 0.227 \\
\hline Sedimentation rate at admission, $\mathrm{mm} / \mathrm{h}(n=999)$ & $22.8 \pm 21.3$ & $24.0 \pm 23.9$ & 0.464 \\
\hline Albuminuria, mg/g of creatinine $(n=785)$ & $5.6 \pm 30.0$ & $6.7 \pm 30.7$ & 0.680 \\
\hline
\end{tabular}

group of patients who worsened, mRS and the good prognosis at 3 months was significantly worse.

\section{Treatment with rt-PA and Relationship to Worse Clinical Outcome}

In the group of patients treated with rt-PA, 39.4\% who did not present clinical reperfusion data developed worsening within
3 months after stroke compared with $3.5 \%$ of patients with reperfusion $(P<0.0001)$. These differences were not significant in the control group (Fig. 2).

In the logistic repression model (Table 3), reperfusion was associated with a significant improvement in clinical outcome (OR 0.08, CI 95\% 0.04-0.17, $P<0.0001$ ), whereas fibrinolytic treatment with rt-PA is a factor independently associated with clinical worsening (OR 4.98, CI 95\% 3.60-6.89, 
Fig. 2 Percentage of worsening in the first 3 months in the group of patients treated with rt-PA and in the control compared to the existence of clinical criteria of reperfusion

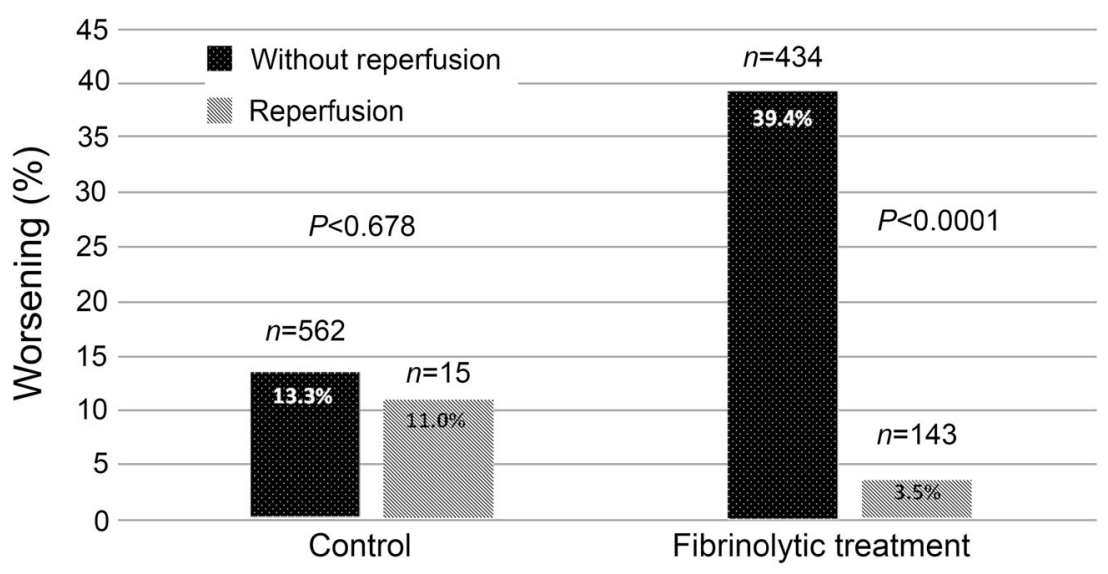

$P<0.0001)$. However, rt-PA treatment associated with reperfusion is the independent factor most strongly associated with patient improvement (OR 0.06, CI 95\% $0.02-0.14$, $P<0.0001)$.

The computed tomography study performed at the 4 th -7 th days reflected a similar lesion volume in patients with and without fibrinolytic treatment $\left(55.2 \pm 80.2 \mathrm{~cm}^{3}\right.$ and $\left.56.5 \pm 87.8 \mathrm{~cm}^{3}, P=0.851\right)$. We found higher lesion volume in patients with worse clinical outcome at 3 months, although the difference did not reach significance $\left(66.7 \pm 87.1 \mathrm{~cm}^{3}\right.$ vs. $\left.51.6 \pm 80.1 \mathrm{~cm}^{3}, P=0.051\right)$. If we included the lesion size in the logistic regression model (Table 3 ), results do not vary (reperfusion (OR 0.07, CI 95\% 0.03-0.24, $P<0.0001$ ); fibrinolytic treatment (OR 4.19, CI 95\% 3.12-7.13, $P<0.0001$ ). In the same line, we determined that anticoagulant or antiplatelet therapy were factors independently associated with clinical prognosis at 3 months in the group with functional outcome worsening (49.3\% with anticoagulant and $50.7 \%$ with antiplatelet, $P=0.119)$.

Only in the group of patients treated with rt-PA, some biological markers associated with inflammation (temperature, leukocytes, C-reactive protein, and erythrocyte sedimentation rate) were significantly higher in patients who did not present clinical reperfusion data (Table 4).

\section{Discussion}

rt-PA is still the gold standard treatment for acute ischemic stroke; however, this is not an innocuous treatment. Although in the clinical practice it has been possible to minimize the risk of hemorrhagic complication, the use of rt-PA in non-reperfused patients is associated with a worse prognosis within 3 months of having an ischemic stroke after ischemic onset.

Therefore, despite the long experience using this treatment, its use should not be considered trivial, and other risks besides hemorrhage must be considered after use. The results in this study confirm that this treatment's benefits happen only when the occluded artery is successfully reperfused. Thus, the absence of response to intravenous rt-PA should force clinicians to start rescue therapies.

After administration in the circulation, rt-PA acts first as an endogenous thrombolytic enzyme; however, then if this enzyme diffuses in the cerebral parenchyma, by crossing the healthy blood-brain barrier and to a higher extend the damaged blood-brain barrier [25], tPA may be able to originate mechanisms involving NMDA receptors signaling [8], ranging from an increase in synaptic plasticity to neurotoxicity, through pathways dependent or independent of tissue plasminogen [10, 11, 17].

Based on preclinical studies, it has been proven that rt-PA may promote neurotoxicity through its action on extrasynaptic GluN2D-containing NMDARs, whereas it could have neuroprotective effects by activating synaptic GluN2A-containing NMDARs [10, 26, 27]. Despite this possible neuroprotective effect, exogenous rt-PA is the paradigm of in vitro or in vivo excitotoxicity mediated by overactivation of NMDARs [10, 14, 17].

rt-PA is secreted as a single-chain (sc) form, which in presence of plasmin is converted in a two-chain (tc) form by cleavage of Arg275-Ile276 region. Both forms have the same fibrinolytic activity, but they differ in the activation of the $\mathrm{N}$ methyl-D-aspartate receptor (NMDAR). The sc-rt-PA form activates the NMDAR, leading to calcium entry and excitotoxic neuronal death, whereas the tc-rt-PA form inhibits NMDAR and its secondary neurotoxicity $[11,28]$. In animal models, the rt-PA-mediated neurotoxicity varies in relation to the ratio between the sc and tc forms [29], data recently confirmed in human [28]. Interestingly, patients treated with rt-PA have been reported to develop more seizures than patients who are not. This potential pro-epileptic effect found in patients is in agreement with the reported capacity of rt-PA (especially its sc form) to promote NMDA receptor signaling.

Experimental and clinical evidence has shown an association between the administration of rt-PA with disruption of the 
Table 3 Crude and adjusted OR of functional outcome worsening (mRS from discharge to 3 months $<0$ ) for fibrinolytic treatment with or without reperfusion

\begin{tabular}{lcccccc}
\hline Independent variables & OR* & CI 95\% & $P$ & OR** & CI 95\% & $P$ \\
\hline History of alcoholism & 1.62 & $1.05-2.49$ & 0.029 & 1.13 & $0.59-2.14$ & 0.710 \\
History of smoking & 0.61 & $0.19-0.98$ & 0.007 & 0.53 & $0.26-1.06$ & 0.074 \\
Start-inclusion time & 0.96 & $0.89-0.99$ & 0.016 & 0.99 & $0.56-1.83$ & 0.957 \\
Start-needle time & 0.85 & $0.43-0.97$ & 0.018 & 0.96 & $0.55-1.77$ & 0.963 \\
Reperfusion & 0.15 & $0.07-0.33$ & $<0.0001$ & 0.08 & $0.04-0.17$ & $<0.0001$ \\
Fibrinolytic treatment & 3.52 & $2.57-4.82$ & $<0.0001$ & 4.98 & $3.60-6.89$ & $<0.0001$ \\
Fibrinolytic treatment by reperfusion & & & & 0.06 & $0.02-0.14$ & $<0.0001$ \\
\hline
\end{tabular}

*Unadjusted logistic regression model

**Adjusted logistic regression model blood-brain barrier and with the consequent risk of edema and hemorrhagic transformation $[11,16,30]$, mainly through the overexpression of metalloproteinases [11, 31, 32]. However, after the clinical experience acquired with the use of rt-PA, these complications are not too common [33, 34].

Following a stroke, neurophysiological processes associated with recovery often begin very early after the onset of stroke (from hours to days) and may plateau in months, depending on the specific neurologic deficit [35]. Our present study confirms our initial hypothesis: in patients treated with rt-PA who do not reperfuse in the first $24 \mathrm{~h}$, the probability of a functional worsening is almost five-fold, independent of an increased risk of hemorrhagic transformation. Therefore, we contemplate that the possible rt-PA-induced toxicity in acute stroke may be the responsible of increase brain damage or delaying recovery mechanisms after the onset. We consider that the inclusion of patients treated with rt-PA from a university hospital that has a stroke unit and a protocolized management gives value and consistency to these conclusions. Although this worsening is likely to be associated with NMDA receptor-mediated neurotoxicity, this study's design — clinical and observational — does not allow confirmation of the molecular mechanism-driven worse outcome. Association of worsening with the presence of markers of inflammation means that the inflammatory environment hinders reperfusion, or that in itself conditions the worse evolution that these patients present. It is thus interesting to note that tPA was also reported to promote transmigration of inflammatory cells across the blood-brain barrier, an effect dependent of NMDA receptors expressed on endothelial cells [36].

Modification of the NIHSS score within $24 \mathrm{~h}$ after the administration of a thrombolytic agent has been shown to be a valid criterion for estimating cerebral reperfusion and with a good relation to recanalization as demonstrated by angiography or ultrasound. However, in the absence of angiographic or ultrasonographic confirmation, the clinical criteria to define effective reperfusion are both unanimous and possibly vary in relation to the sample studied. An improvement of $\geq 10$ points or $\geq 20 \%$ between baseline and at $24 \mathrm{~h}$ has nevertheless shown a good relationship [37-40]. Here, we used the cutoff point $\geq 8$ because the sensitivity and specificity were higher (with a cutoff point $\geq 10$, the sensitivity was $84.3 \%$, but the specificity was $86.1 \%$ ).

Despite the efficacy and safety of fibrinolytic treatment in lacunar infarcts [41, 42], we decided to exclude these patients from the study for several reasons: (1) in an unknown proportion of lacunar infarcts, the pathologic basis is lipohyalinosis, which should not be a subsidiary of the administration of rt-PA [42]. (2) Markers of fibrinolysis, coagulation, endothelial, and inflammation are different [43], and some of these factors may condition the response to fibrinolytic treatment. (3) Twenty percent of patients with lacunar syndrome do not develop lacunar infarction, and 5 to $30 \%$ of lacunar infarcts are the result of cerebral embolisms [44]. (4) The existence of penumbra in small vessel disease is questionable [45]. (5) The immediate and remote
Table 4 Biological signatures of ischemic stroke patients treated with rt-PA by reperfusion groups

\begin{tabular}{lccc}
\hline & $\begin{array}{l}\text { No reperfusion } \\
n=434\end{array}$ & $\begin{array}{l}\text { Reperfusion } \\
n=143\end{array}$ & $P$ \\
\hline Axillary temperature at admission, ${ }^{\circ} \mathrm{C}(n=577)$ & $36.4 \pm 0.6$ & $36.0 \pm 0$ & $<0.0001$ \\
Blood glucose at admission, $\mathrm{mg} / \mathrm{dL}(n=577)$ & $140.2 \pm 54.5$ & $122.0 \pm 31.4$ & $<0.0001$ \\
Leukocytes at admission, $\times 10^{3} / \mathrm{mmc}(n=577)$ & $9.4 \pm 3.5$ & $7.8 \pm 2.7$ & $<0.0001$ \\
$\begin{array}{l}\text { Fibrinogen at admission, } \mathrm{mg} / \mathrm{dL}(n=505) \\
\text { C-reactive protein at admission, } \mathrm{mg} / \mathrm{dL}\end{array} \quad 422.1 \pm 118.2$ & $398.5 \pm 107.3$ & 0.053 \\
$\quad(n=545)$ & $4.4 \pm 5.0$ & $2.3 \pm 3.6$ & $<0.0001$ \\
$\begin{array}{l}\text { Sedimentation rate at admission, } \mathrm{mm} / \mathrm{h} \\
(n=565)\end{array}$ & $24.7 \pm 23.4$ & $14.7 \pm 16.9$ & $<0.0001$ \\
\begin{tabular}{l} 
Albuminuria, $\mathrm{mg} / \mathrm{g}$ of creatinine $(n=415)$ \\
\hline
\end{tabular} & $7.4 \pm 33.2$ & $6.4 \pm 33.3$ & 0.795 \\
\hline
\end{tabular}


mechanisms of action of rt-PA may be different; due to the integrity of the blood-brain barrier, the rt-PA does not overflow and may have a neuroprotective effect or may condition a progression of white matter lesion, but not neuronal toxicity [46]. In the 21 patients with lacunar infarcts treated with rt-PA and excluded from our analysis, only $2(9.5 \%)$ worsened in the first 3 months (data not shown), revealing the existence of a probably different rt-PA toxicity mechanism.

Our study has limitations, which, while not calling into question the validity of the results, imply the need for further prospective studies. We do not have the data on the dose of rtPA given or the topography of the lesion (it is possible that neurotoxicity affects cortical and subcortical infarcts differently). Also, the best control group is not patients who do not receive fibrinolytic treatment but those who underwent thrombectomy without rt-PA, but the number of patients that meet this characteristic in our series was too small.

\section{Summary}

In summary, administration of rt-PA intravenously or intraarterially may be associated with a higher risk of functional deterioration in the first 3 months if reperfusion within the first $24 \mathrm{~h}$ does not happen. We thus postulate that patients treated with rt-PA without an effective immediate reperfusion should be treated with appropriate drugs to neutralize possible adverse effects of rt-PA, including its ability to promote NMDA receptors and subsequent neurotoxicity.

Acknowledgements The article was reviewed for grammar through an Elsevier service.

Sources of Funding This study was supported by the Spanish Ministry of Economy and Competitiveness (SAF2014-56336-R), Xunta de Galicia (Consellería de Educación: GRC2014/027 and Axencia Galega de Innovación), Instituto de Salud Carlos III (PI13/00292 and PI14/01879), Spanish Research Network on Cerebrovascular Diseases RETICS-INVICTUS (RD16/0019), European Union FEDER program. Furthermore, T. Sobrino (CP12/03121) and F. Campos (CP14/00154) are recipients of research contracts (Miguel Servet Program of Instituto de Salud Carlos III). Clara Correa-Paz is the recipient of an FPI fellowship (BES-2015-073933) Spanish Ministry of Economy and Competitiveness. The sponsors did not participate in study design, collection, analysis, interpretation of the data, in writing the report, or in the decision to submit the paper for publication.

\section{Compliance with Ethical Standards}

Conflict of Interest The authors declare that they have no conflicts of interest.

Ethical Approval and Patient Consent This research was carried out in accordance with the Declaration of Helsinki of the World Medical Association (2008) and approved by the Ethics Committee of the Servizo Galego de Saúde. Informed consent was obtained from each patient or their relatives after full explanation of the procedures.
Open Access This article is distributed under the terms of the Creative Commons Attribution 4.0 International License (http:// creativecommons.org/licenses/by/4.0/), which permits unrestricted use, distribution, and reproduction in any medium, provided you give appropriate credit to the original author(s) and the source, provide a link to the Creative Commons license, and indicate if changes were made.

\section{References}

1. NINDS. Tissue plasminogen activator for acute ischemic stroke. N Engl J Med. 1995;333:1581-7.

2. Lees KR, Bluhmki E, von Kummer R, Brott TG, Toni D, Grotta JC, et al. Time to treatment with intravenous alteplase and outcome in stroke: an updated pooled analysis of ECASS, ATLANTIS, NINDS, and EPITHET trials. Lancet. 2010;375(9727):1695-703.

3. Goyal M, Demchuk AM, Menon BK, Eesa M, Rempel JL, Thornton J, et al. Randomized assessment of rapid endovascular treatment of ischemic stroke. N Engl J Med. 2015;372(11):1019 30

4. Campbell BC, Mitchell PJ, Kleinig TJ, Dewey HM, Churilov L, Yassi N, et al. Endovascular therapy for ischemic stroke with perfusion-imaging selection. N Engl J Med. 2015;372(11):100918 .

5. Berkhemer OA, Dippel DW. Intra-arterial therapy for acute ischaemic stroke. Lancet Neurol. 2016;15(11):1105-7.

6. Coutinho JM, Liebeskind DS, Slater LA, Nogueira RG, Clark W, Dávalos A, et al. Combined intravenous thrombolysis and thrombectomy vs thrombectomy alone for acute ischemic stroke: a pooled analysis of the SWIFT and START studies. JAMA Neurol. 2017;74(3):268-74.

7. Abilleira S, Ribera A, Cardona P, Rubiera M, López-Cancio E, Amaro S, et al. Outcomes after direct thrombectomy or combined intravenous and endovascular treatment are not different. Stroke. 2017;48(2):375-8.

8. Nicole O, Docagne F, Ali C, Margaill I, Carmeliet P, Mackenzie ET, et al. The proteolytic activity of tissue-plasminogen activator enhances NMDA receptor-mediated signaling. Nat Med. 2001;7(1): 59-64.

9. Park L, Gallo EF, Anrather J, Wang G, Norris EH, Paul J, et al. Key role of tissue plasminogen activator in neurovascular coupling. Proc Natl Acad Sci U S A. 2008;105(3):1073-8.

10. Chevilley A, Lesept F, Lenoir S, Ali C, Parcq J, Vivien D. Impacts of tissue-type plasminogen activator (tPA) on neuronal survival. Front Cell Neurosci. 2015;9:415.

11. Docagne F, Parcq J, Lijnen R, Ali C, Vivien D. Understanding the functions of endogenous and exogenous tissue-type plasminogen activator during stroke. Stroke. 2015;46(1):314-20.

12. Fan M, Xu H, Wang L, Luo H, Zhu X, Cai P, et al. Tissue plasminogen activator neurotoxicity is neutralized by recombinant ADAMS 13. Sci Report. 2016;6:25971.

13. Lesept F, Chevilley A, Jezequel J, Ladépêche L, Macrez R, Aimable M, et al. Tissue-type plasminogen activator controls neuronal death by raising surface dynamics of extrasynaptic NMDA receptors. Cell Death Dis. 2016;7(11):e2466.

14. Abu Fanne R, Nassar T, Yarovoi S, Rayan A, Lamensdorf I, Karakoveski M, et al. Blood-brain barrier permeability and tPAmediated neurotoxicity. Neuropharmacology. 2010;58(7):972-80.

15. Wang W, Li M, Chen Q, Wang J. Hemorrhagic transformation after tissue plasminogen activator reperfusion therapy for ischemic stroke: mechanisms, models, and biomarkers. Mol Neurobiol. 2015;52(3):1572-9. 
16. Kidwell CS, Latour L, Saver JL, Alger JR, Starkman S, Duckwiler $\mathrm{G}$, et al. Thrombolytic toxicity: blood brain barrier disruption in human ischemic stroke. Cerebrovasc Dis. 2008;25(4):338-43.

17. Yepes M, Roussel BD, Ali C, Vivien D. Tissue-type plasminogen activator in the ischemic brain: more than a thrombolytic. Trends Neurosci. 2009;32(1):48-55.

18. Hacke W, Kaste M, Fieschi C, von Kummer R, Dávalos A, Meier $\mathrm{D}$, et al. Randomised double-blind placebo-controlled trial of thrombolytic therapy withg intravenous alteplase in acute ischaemic (ECASS II): second European-Australasian acute stroke study investigators. Lancet. 1998;352(9136):1245-51.

19. The European Stroke Organisation (ESO) Executive Committee; ESO Writing Committee. Guidelines for management of ischaemic stroke and transients ischaemic attack 2008. Cerebrovasc Dis. 2008;25:457-507.

20. Bamford J, Sandercock P, Dennis M, Burn J, Warlow C. Classification and natural history of clinically identifiable subtypes of cerebral infarction. Lancet. 1991;337(8756):1521-6.

21. Adams HP Jr, Bendixen BH, Kappelle LJ, Biller J, Love BB, Gordon DL, et al. Classification of subtype of acute ischemic stroke: definitions for use in multicenter clinical trial: TOAST: Trial of Org 10172 in Acute Stroke Treatment. Stroke. 1993;24(1):35-41.

22. Muresan IP, Favrole P, Levy P, Andreux F, Marro B, Alamowitch S. Very early neurologic improvement after intravenous thrombolysis. Arch Neurol. 2010;67(11):1323-8.

23. Rodríguez-Yáñez M, Sobrino T, Arias S, Vázquez-Herrero F, Brea D, Blanco M, et al. Early biomarkers of clinical-diffusion mismatch in acute ischemic stroke. Stroke. 2011;42(10):2813-8.

24. Saposnik G, Di Legge S, Webster F, Hachinski V. Predictors of major neurologic improvement after thrombolysis in acute stroke. Neurology. 2005;65(8):1169-74.

25. Benchenane K, Berezowski V, Ali C, Fernández-Monreal M, López-Atalaya JP, Brillault J, et al. Tissue-type plasminogen activator crosses the intact blood-brain barrier by low-density lipoprotein receptor-related protein-mediated transcytosis. Circulation. 2005;111(17):2241-9.

26. Montagne A, Hébert M, Jullienne A, Lespt F, Le Béhot A, Louessard M, et al. Memantine improves safety of thrombolysis for stroke. Stroke. 2012;43(10):2774-81.

27. Wu F, Echeverry R, Wu J, An J, Haile WB, Cooper DS, et al. Tissue-type plasminogen activator protects neurons from excitotoxin-induced cell death via activation of the ERK1/2CREB-ATF3 signaling pathway. Mol Cell Neurosci. 2013;52:9-19.

28. Leys D, Hommet Y, Jacquet C, Moulin S, Sibon I, Mas JL, et al. Proportion of single-chain recombinant tissue plasminogen activator and outcome after stroke. Neurology. 2016;87(23):2416-26.

29. Parcq J, Bertrand T, Montagne A, Baron AF, Macrez R, Billard JM, et al. Unveiling an exceptional zymogen: the single-chain form of tPA is a selective activator of NMDA receptor-dependent signaling and neurotoxicity. Cell Death Differ. 2012;19(12):1983-91.

30. Niego B, Medcalf RL. Plasmin-dependent modulation of the bloodbrain barrier: a major consideration during tPA-induced thrombolysis? J Cereb Blood Flow Metab. 2014;34(8):1283-96.

31. Castellanos M, Leira R, Serena J, Pumar JM, Lizasoain I, Castillo J, et al. Plasma metalloproteinase-9 concentration predicts hemorrhagic transformation in acute ischemic stroke. Stroke. 2003;34(1):40-6.
32. Fernández-Cadenas I, Del Río-Espínola A, Carrera C, DominguesMontanari S, Mendióroz M, Delgado P, et al. Role of MMP9 gene in hemorrhagic transformations after tissue-type plasminogen activator treatment in stroke patients. Stroke. 2012;43(5):1398-400.

33. Kanawawa M, Takahashi T, Nishizawa M, Shimohata T. Therapeutic strategies to attenuate hemorrhagic transformation after tissue plasminogen activator treatment for acute ischemic stroke. J Atheroscler Thromb. 2017;24(3):240-53.

34. Wahlgren N, Ahmed N, Dávalos A, Ford GA, Grond M, Hacke W, et al. Thrombolysis with alteplase for acute ischemic stroke in the safe implementation of thrombolysis in stroke-monitoring study (SITS-MOST): an observational study. Lancet. 2007;369(9558): 275-82.

35. Seitz RJ, Donnan GA. Recovery potential after acute stroke. Front Neurol. 2015;6:238.

36. Macrez R, Vivien D, Docagne F. Role of endothelial NMDA receptors in a mouse model of multiple sclerosis. Med Sci (Paris). 2016;32(12):1068-71.

37. Kakuda W, Hamilton S, Thijs VN, Lansberg MG, Kemp S, Skalabrin E, et al. Optimal outcome measures for detecting clinical benefits of early reperfusion: insights from the DEFUSE Study. J Stroke Cerebrovasc Dis. 2008;17(4):235-40.

38. Nam HS, Lee KY, Han SW, Kim SH, Lee JY, Ahn SH, et al. Prediction of long-term outcome by percent improvement after the first day of thrombolytic treatment in stroke patients. J Neurol Sci. 2009;281(1-2):69-73.

39. Kharitonova T, Mikulik R, Roine RO, Soinne L, Ahmed N, Wahlgren N, et al. Association of early National Institute of Health Stroke Scale improvement with vessel recanalization and functional outcome after intravenous thrombolysis in ischemic stroke. Stroke. 2011;42(6):1638-43.

40. Kharitonova TV, Melo TP, Andersen G, Egido JA, Castillo J, Wahlgren $\mathrm{N}$, et al. Importance of cerebral artery recanalization in patients with stroke with and without neurological improvement after intravenous thrombolysis. Stroke. 2013;44(9):2513-8.

41. Griebe M, Fischer E, Kablau M, Eisele P, Wolf ME, Chatzikonstantinou A, et al. Thrombolysis in patients with lacunar stroke is safe: an observational study. J Neurol. 2014;261(2):40511.

42. Pantoni L, Fierini F, Poggesi A. Thrombolysis in acute stroke patients with cerebral small vessel disease. Cerebrovasc Dis. 2014;37(1):5-13.

43. Wiseman S, Marlborough F, Doubal F, Webb DJ, Wardlaw J. Blood markers of coagulation, fibrinolysis, endothelial dysfunction and inflammation in lacunar stroke versus non-lacunar stroke and nonstroke: systematic review and meta-analysis. Cerebrovasc Dis. 2014;37(1):64-75.

44. Moncayo J, Devuyst G, Van Melle G, Bogousslavsky J. Coexisting causes of ischemic stroke. Arch Neurol. 2000;57(8):1139-44.

45. Föster A, Kerl HU, Wenz H, Brockmann MA, Nölte I, Groden C. Diffusion- and perfusion-weighted imaging in acute lacunar infarction: is there a mismatch? PLoS One. 2013;8(10):e77428.

46. van Overbeek E, Staals J, Knottnerus ILH, ten Cate H, van Oostenbrugge RJ. Plasma tPA-activity and progression of cerebral white matter hyperintensities in lacunar stroke patients. PLoS One. 2016;11(3):e0150740. 